\title{
Five-Part Pentameric Nanocomplex Shows Improved Efficacy of Doxorubicin in CD44+ Cancer Cells
}

\author{
Nathan Beals, ${ }^{\dagger}$ Praveena S. Thiagarajan, ${ }^{\ddagger}$ Eric Soehnlen, ${ }^{\dagger}$ Arijit Das, ${ }^{\dagger, \perp}$ Ofer Reizes, ${ }^{\ddagger}, \S_{,}$
}

Justin D. Lathia, ${ }^{\ddagger},, \| l$ and Soumitra Basu* ${ }^{*} \dagger \odot$

${ }^{\dagger}$ Department of Chemistry and Biochemistry, Kent State University, Kent, Ohio 44242, United States

${ }^{\ddagger}$ Department of Cellular and Molecular Medicine, Lerner Research Institute, Cleveland Clinic, Cleveland, Ohio 44195, United States

${ }^{\S}$ Department of Molecular Medicine, Cleveland Clinic Lerner College of Medicine of Case Western Reserve University, Cleveland, Ohio 44195, United States

"Case Comprehensive Cancer Center, Cleveland, Ohio 44106-5065, United States

\section{Supporting Information}

\begin{abstract}
The CD44 receptor is common among many cancer types where overexpression is synonymous with poor prognosis in prostate, glioma, and breast cancer. More notably CD44 overexpression has been shown in a number of different cancer stem cells (CSC) which are present in many solid tumors and drive growth, recurrence, and resistance to conventional therapies. Triple negative breast cancer CSCs correlate to worse prognosis and early relapse due to higher drug resistance and increased tumor heterogeneity and thus are prime targets for anticancer therapy. To specifically target cells overexpressing CD44 receptors, including CSCs, we synthesized a pentameric nanocomplex (PNC) containing gold nanoparticles, doxorubicin (Dox) conjugated to thiolated hyaluronic acid via an acid-labile hydrazone bond, and thiolated poly(ethylene glycol) DNA CD44 aptamer. In vitro drug release was

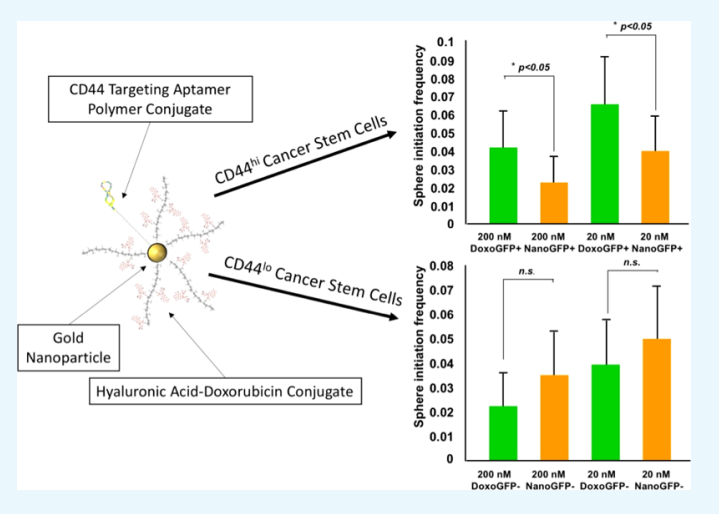
highest at $8 \mathrm{~h}$ time point at acidic $\mathrm{pH}(\mathrm{pH} 4.7)$ and in $10 \mathrm{mM}$ glutathione.

The PNC is almost an order of magnitude more effective than Dox alone in CD44+ cells versus CD44 low cells. Functionally, the PNC reduced CSC self-renewal. The PNC provides a therapeutic strategy that can improve the efficiency of Dox and decrease nontargeted toxicity thereby prolonging its use to individual patients.
\end{abstract}

\section{INTRODUCTION}

Targeting cell surface receptors that are overexpressed only under disease conditions is a common strategy used to specifically target cancer cells for anticancer drug delivery. ${ }^{1}$ One such receptor is CD44, which is a transmembrane protein that mediates communication and adhesion among cells, interactions between cell and extracellular matrix, cell migration, and cell survival and growth. ${ }^{2}$ This receptor, which binds hyaluronic acid (HA), is overexpressed in many types of cancers, such as triple negative breast cancer (TNBC), 3,4 hepatocellular carcinoma, ${ }^{5}$ colon, ${ }^{6,7}$ head and neck, ${ }^{8}$ and ovarian. ${ }^{9,10} \mathrm{CD} 44$ is also expressed in TNBC cancer stem cells (CSCs), and it is known that the presence of CSCs has a high correlation with tumor progression and early recurrence. ${ }^{4,10-14}$ Sole targeting of the tumorigenic regions is considered to be insufficient for the treatment of aggressive tumors, especially in the case of late stage cancers. ${ }^{15-18}$ Triple negative breast cancers make up $15-20 \%$ of all breast cancers and are characterized by high rates of early relapse within the first 5 years because of drug resistance and the heterogeneous nature of the disease. ${ }^{19,20}$ Current treatment mechanisms consisting of chemotherapeutics, such as anthracyclines, taxanes, and platinum-based drugs, rarely achieve a pathologically complete response (pCR) in patients with TNBC. ${ }^{21}$

Targeted nanoparticle delivery systems have the unique ability to overcome the wide variations in tumorigenic cells along with negative side effects of anticancer small molecules. ${ }^{22-26}$ One characteristic that makes the nanoparticle delivery systems advantageous when compared with free drug treatment is passive targeting through enhanced permeability and retention (EPR), where circulating particles can readily accumulate in tumors due to their porous epithelial cell lining. ${ }^{27}$ Specifically, PEGylated gold nanoparticles (AuNP) have been shown to collect more efficiently on the basis of their hydrodynamic size, with sizes ranging from 60 to $80 \mathrm{~nm}$ being the most effective. ${ }^{28}$ To further accentuate specific cellular targeting, nanoparticles have been designed to incorporate multiple functionalities, such as photodynamic therapy, ${ }^{29}$ drug release through sulfide ligand exchange, ${ }^{30}$ small molecule acid-labile release, ${ }^{31,32}$ delivery of synergistic anti-

Received: August 11, 2017

Accepted: October 27, 2017

Published: November 9, 2017 
i)

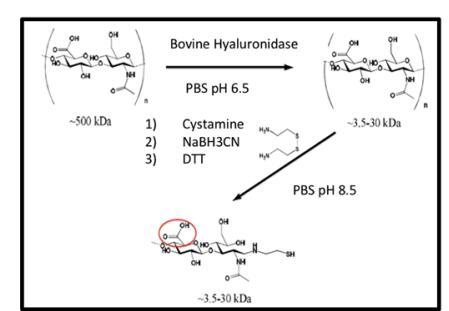

Thiolated Hyaluronic Acid (HASH)

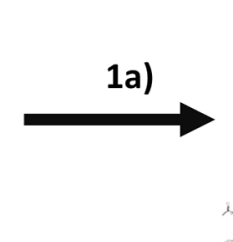

ii)
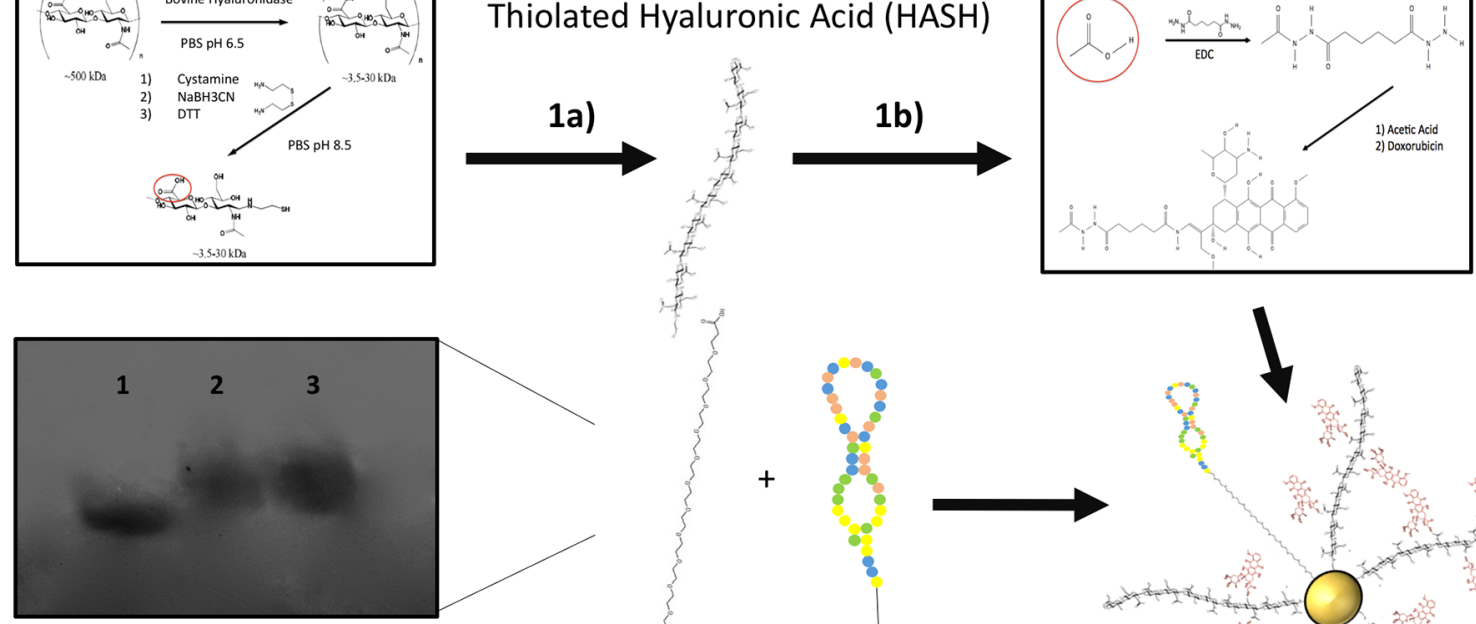

iii)
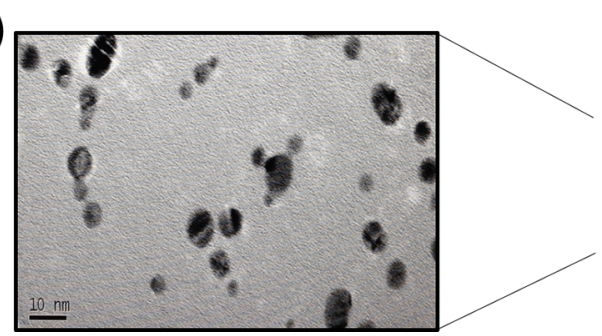

PEG
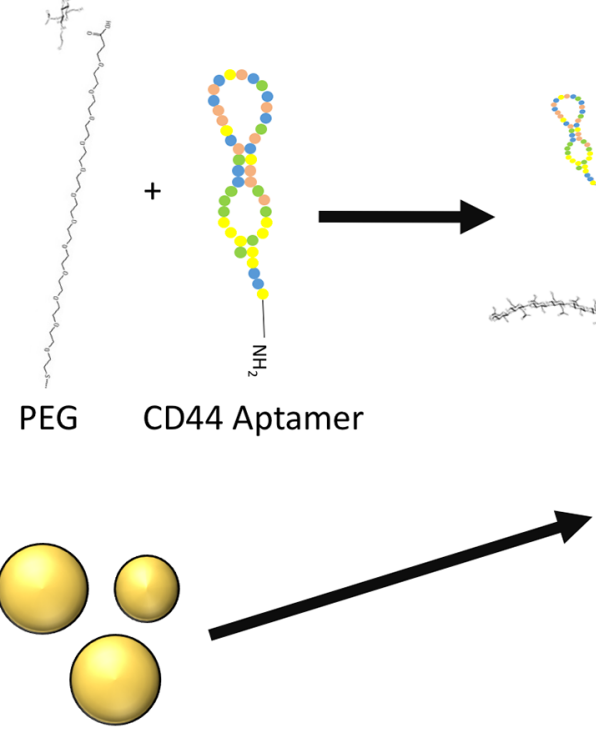

Figure 1. Schematic of the synthesis of PNC. (1a) Synthesis of hyaluronic acid thiol derivative (HASH). (1b) Conjugation of doxorubicin via acidlabile linkage. (2) Middle left. Polyacrylamide gel electrophoresis (PAGE) showing migration differences between CD44 aptamer (1) and unpurified (2) and purified (3) CD44 phosphothioate aptamer conjugated to bifunctional 5K poly(ethylene glycol) (PEG). (3) Bottom left. Transmission electron microscopy (TEM) image of AuNP synthesized by the sodium borohydride reduction method. The average particle size was measured as $4.2 \pm 1 \mathrm{~nm}$. Bottom right. Each component was mixed to form the PNC (AuNP + HASH/Dox-PEGylated CD44 aptamer).

cancer drugs ${ }^{33}$ and cellular targeting through conjugated aptamers and antibodies. ${ }^{34-36}$ Among the variations of nanoparticles used for drug delivery, AuNPs have been used extensively for their characteristic biological inertness, ${ }^{37}$ controllable size $^{38}$ and a thiolphilic surface for ligand interactions. $^{39}$

Because of the versatility in the number of ways HA can be used, there are many reports of CD44-targeted nanoparticle complexes. $^{40-43}$ Specifically, Hammond et al. used HA as a coating agent for CD44-targeted layer by layer nanoparticles for the codelivery of chemotherapeutic agents and siRNA. ${ }^{44}$ Other examples have used $\mathrm{HA}$ as the scaffold for polymeric nanoparticles, which can deliver conjugated small molecules ${ }^{45}$ and RNA. ${ }^{26}$ In recent years, nanoparticles have been used to target CD44 overexpressing CSCs. ${ }^{5,46,47}$ However, a major drawback of most of the current clinical strategies is their inability to effectively kill CSCs that are instrumental in maintaining tumor drug resistance and a protumorigenic microenvironment. We have designed and synthesized a pentameric nanoparticle complex (PNC) for targeted drug delivery of doxorubicin (Dox) for overexpressing CD44 tumorgenic cells and TNBC CSCs to achieve improved cytotoxicity compared with the free drug. The five-component PNC looks to combine strategies of inorganic and polymeric nanoparticles by incorporating thiolated HA to stabilize AuNP and for increased drug loading, while using a CD44 DNA aptamer for cellular targeting. We believe that this will serve as a novel platform that could be used to specifically target TNBC
CSCs and potentially improve upon current treatment strategies.

\section{RESULTS AND DISCUSSION}

Establishing the Identity of the Five-Part (Pentameric) Nanocomplex. To target the CD44 positive cancer cells and the triple negative breast cancer stem cells (TNBC CSCs) we designed and synthesized a PNC, so named because the nanocomplex is comprised of five components. The PNC utilized optimized functionalities to address two major criticisms common to effective drug delivery: (i) targeting of cancerous cells to reduce potential life-threatening side effects and (ii) loading enough drug molecules to elicit an effective dose response. A schematic of the PNC is shown in Figure 1 consisting of Dox conjugated to the naturally occurring polysaccharide hyaluronic acid (HA) and a thiol containing PEGylated CD44 DNA phosphorothioate aptamer capable of specifically delivering small molecule drugs to cells with overexpression of CD44. The CD44 phosphorothioate aptamer ${ }^{48}$ is a targeting ligand specifically selected to bind to the CD44 receptor, enhancing the recognition of cells that overexpress these receptors. The phosphorothioate-modified aptamer was used to provide stability against nucleases, making it advantageous for use with nanoparticle drug delivery with potentially long circulation times. ${ }^{49}$ To maximize drug loading while maintaining controlled intracellular release, the HA polymer was first thiolated at the reducing end to facilitate binding onto the AuNP surface and then conjugated to Dox 
that led to multiple drug loading per polymer molecule. This scheme maximized the availability of functional groups for drug loading in comparison to many of the previously reported polymeric nanoparticle complexes, where available functional groups were lost due to cross-linking. ${ }^{50}$ Our nanoparticle complex also offers an advantage in terms of drug loading compared with inorganic nanoparticles, which needs a mixture of stabilizing ligands and drugs on the nanoparticle surface, resulting in the stabilizing ligands occupying valuable drug binding sites. An acid-labile hydrazone bond connects each of the drug molecules to the polymer, which preferentially breaks in acidic $\mathrm{pH}$ environment found in lysosomal compartments of cells. Additionally, cancer cells often have lower intracellular $\mathrm{pH}$ $(\sim 5.8-7)$ which may also help in the release of the drug molecule. ${ }^{51}$ The complex combines the ability of the AuNP to undergo high drug loading with the precision of aptamer recognition of cell surface receptors for more efficient drug delivery.

On the basis of previous reports, we decided to use a sub 5 $\mathrm{nm}$ AuNP because of its desirable physical traits, which makes it suitable to act as the core of the PNC. This smaller size has been shown to be better for the post drug release excretion of the naked nanoparticles, for example, clearance through the pores of the kidney that are $5 \mathrm{~nm}$ in diameter. ${ }^{52}$ We synthesized AuNP by the reduction of $\mathrm{HAuCl}_{3}$ with $\mathrm{NaBH}_{4}$. The size of the nanoparticles was determined by $\mathrm{UV}$-vis spectrophotometry (Figure S1), TEM (Figures 1(iii) and S2), and dynamic light scattering (DLS) (Table 1). The TEM and DLS data indicate

Table 1. Dynamic Light Scattering (DLS) Measurements Indicate Intrapolymer Interactions Play a Role in PNC Size ${ }^{a}$

\begin{tabular}{lc}
\multicolumn{1}{c}{ complex } & average size $(\mathrm{nm})$ \\
AuNP & $4( \pm 2)$ \\
AuNP-HASHDox & $50( \pm 3)$ \\
AuNP-PEG & $48( \pm 26)$ \\
PNC & $60( \pm 5)$ \\
AuNP-HASH & $160( \pm 48)$
\end{tabular}

${ }^{a}$ At pH 6.5, the average hydrodynamic diameter of the AuNP and AuNP with varying types of HASH derivatives was tested in triplets using a Nanoanalyzer DLS machine.

that the synthesized nanoparticles were an average of 4.2 and $3.7 \mathrm{~nm}$ in size, respectively. The size measurement from multiple preparations demonstrated that the size of the synthesized nanoparticles is very similar, indicating the reproducibility of our method (Table S1).

To improve cellular specificity of the nanoparticle complex, a targeting aptamer for CD44 would have to be appropriately attached to the nanoparticle, ensuring its availability to recognize the targeted protein, the CD44 receptor. To accomplish this, a DNA aptamer was synthesized with an amine-functionalized linker at the $3^{\prime}$ end to facilitate conjugation via the $-\mathrm{COOH}$ of a bifunctional poly(ethylene glycol) (PEG) (5 kDa) using an $\mathrm{N}$-(3-(dimethylamino)propyl)- $N^{\prime}$-ethylcarbodiimide hydrochloride/ $N$-hydroxysuccinimide (EDC/NHS)-ester cross-coupling. ${ }^{53}$ Successful PEGylation of the aptamer was detected (Figure 1(ii), lanes 2 and 3) by analysis on a $15 \%$ denaturing polyacrylamide gel that showed its slower migration in comparison to that of the free aptamer (Figure 1(ii), lane 1). The slower migration of the PEGylated aptamer was expected because of the addition of a 5 $\mathrm{kDa}$ PEG. A mutant version of the PEGylated aptamer was synthesized using identical chemical strategy. Incorporation of the thiolated-PEG-aptamer in PNC was detected by using a radiolabeled version of the CD44 aptamer, which was then mixed with the "naked" AuNP, followed by HASH-Dox (Figure 2 ). Analysis of the products on an $1 \%$ agarose gel showed the

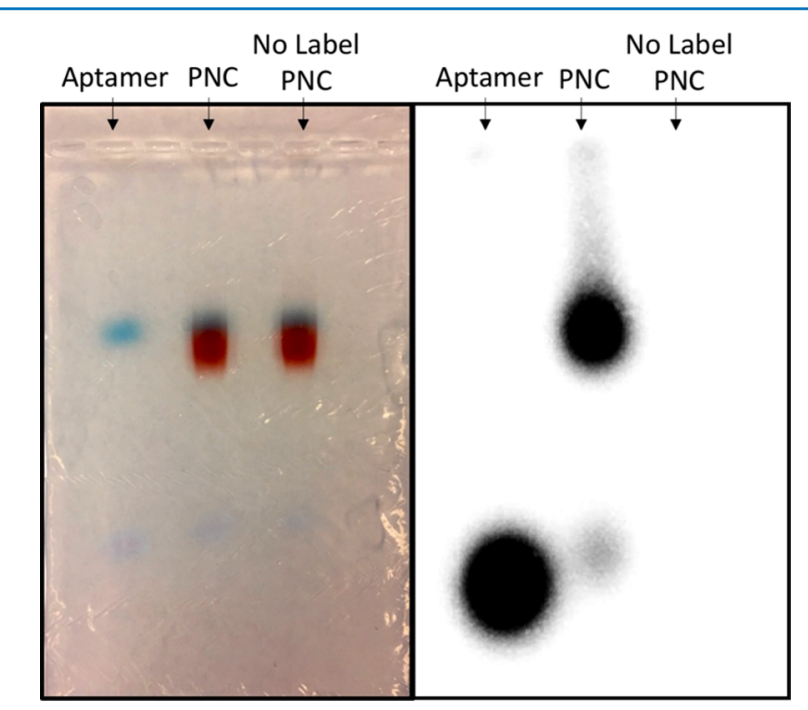

Figure 2. PEGylated CD44 aptamer is conjugated to the PNC complex show though radiolabeled agarose gel migration. (Left) Bright field image of radiolabeled PEGylated CD44 aptamer, the PNC complex with radiolabeled PEGylated CD44 aptamer, and a nonlabeled PEGylated CD44 PNC complex ran in 1\% agarose gel. (Right) Phosphoimage of the same gel, showing the migration of the labeled aptamer is dependent on AuNP conjugation.

presence of the free conjugated aptamer (Figure 2, lane 1), labeled PNC (Figure 2, lane 2) and unlabeled PNC (Figure 2, lane 3). A substantial reduction in the migration of the labeled PEG-aptamer in lane 2 compared to that of the free radiolabeled PEG-aptamer in lane 1 implies that its mostly a part of the PNC. Quantification using Image J showed $\sim 1.35$ nmol aptamer was complexed to approximately each nmol of AuNP, indicating $\sim 90 \%$ loading. The same experiment was performed except the order of polymer addition was switched, meaning the labeled aptamer was added after the addition of the HASH-Dox (Figure S3). In this scenario, incorporation of the aptamer into the complex was about $50 \%$, indicating the importance of the order of addition of each component during the preparation of the PNC. To further establish that the PEGaptamer is indeed a part of the PNC, we compared the migration of AuNP-HASHDox versus that of the PNC complex in $1 \%$ agarose gel (Figure S4). The PNC was observed to run slower than the AuNP-HASHDox, which can be explained if we consider that the HASH-Dox is about $10 \mathrm{kDa}$, whereas the PEG-aptamer conjugate is about $14 \mathrm{kDa}$ in size, presumably creating a larger nanoparticle (as discussed later, the DLS data also corroborates these data).

For drug loading and stability of the PNC, we utilized the naturally occurring polysaccharide $\mathrm{HA}$ that has been used in a variety of biomaterial. ${ }^{54-56}$ To facilitate binding onto the AuNP, HA molecules were thiolated at their reducing end and subsequently conjugated to multiple Dox molecules via an acidlabile Schiff base linkage. Briefly, the $-\mathrm{COOH}$ groups of $\mathrm{HA}$ were modified with adipic dihydrazide $(\mathrm{ADH})$ and the azide was linked to Dox, forming a Schiff base linkage (HASH-Dox, Figure 1(i)). This allowed incorporation of two important 
functionalities: (i) a controllable acid-labile release mechanism that results in limited release at physiological $\mathrm{pH}$ during extracellular circulation thus potentially reducing nonspecific drug cytotoxicity and (ii) more available functionalities for drug loading outside the AuNP surface. The HASH-Dox loading was quantified using the characteristic Dox peak at $490 \mathrm{~nm}$ measured by UV-vis spectrophotometry (Figure S5). Also, HASH-Dox polymer was shown to be fully loaded, as no visible HASH-Dox could be assessed after dialysis. Together, these showed that there are 100 HASH-Dox polymers loaded per nanoparticle based on the conjugated conditions and full loading. To further confirm conjugation of HA to Dox, we used NMR and IR to verify the formation of the hydrazone linkage between the two components in the final HASH-Dox polymer (Figures S6-S9). The presence of Dox on the HASH polymer was observed via ${ }^{1} \mathrm{H}$ NMR spectrum, which showed the characteristic resonances for Dox at 1.2, 1.9, 2.2, 2.8, and 2.9 ppm which were absent in the HASH ${ }^{1} \mathrm{H}$ NMR spectrum (see Figures S6 and S7). ${ }^{57-60}$ Additionally, IR spectrophotometry has been performed on these complexes and the HASH-Dox showed characteristics that can be ascribed to imine formation (see Figures S8 and S9). In the HASH-Dox polymer, peaks ranging from 1650 to $1750 \mathrm{~nm}$ were observed, whereas no increase at $1654 \mathrm{~nm}$ was detected in the $\mathrm{HASH}-\mathrm{ADH}$ polymer spectrum, indicating the Dox conjugation to the adipic dihydrazide via hydrazone bonding. Many nanoparticle complexes tether small molecules to the gold surface, creating potential competition for nanoparticle space with the stabilizing ligands. ${ }^{29,61}$ For example, in a previous report Dox was directly loaded on $5 \mathrm{~nm}$ AuNP and the loading was about 150 molecules per AuNP, whereas in our case, using the HA for drug loading we detected about 270 per AuNP $(4.2 \mathrm{~nm}) .^{61}$

For the conjugate to be therapeutically viable, the PNC has to remain stable at physiological conditions. Stability studies with $\mathrm{PNC}$ in concentrations ranging from $10 \mathrm{mM}$ to $1 \mathrm{M} \mathrm{NaCl}$ salt solution were performed to increase the stringency of the assay. The aggregation was assessed visually and via UV-vis spectrophotometry, where the $515 \mathrm{~nm}$ peak was monitored. It has been observed that AuNP instability and aggregation would cause a redshift and broadening of the AuNP UV peak (Figure S10). ${ }^{62}$ All nanocomplexes showed stability in $1 \mathrm{M} \mathrm{NaCl}$, which greatly exceeds the blood salt concentrations $(\sim 150 \mathrm{mM})$, showing the HASH-Dox polymer is extremely stable even at high salt. ${ }^{63}$ Besides stability, the sizing of the nanoparticle is also important for effective tumor and cell targeting. It has been shown that polymer-coated gold nanoparticles with a hydrodynamic diameter of $60-80 \mathrm{~nm}$ collect most readily in tumor sites through EPR. ${ }^{64,65}$ Dynamic Light Scattering (DLS), zeta potential, and polydispersity index (PDI) were used to verify the size and charge of the PNC after addition of each component (Tables 1, S2 and S3). The low molecular weight HASH showed a diameter of $160 \mathrm{~nm}$ when coated onto AuNP. Hyaluronic acid is highly charged due to the low $\mathrm{p} K_{\mathrm{a}}$ of the free carboxyl groups having a zeta potential of $-44.1 \mathrm{mV} .^{66}$ However, the AuNP-HASHDox diameter $(50 \mathrm{~nm})$ was distinctly smaller, perhaps due to interactions between the conjugated Dox and unreacted HA functional groups. The primary amine of Dox has been reported to have $\mathrm{p} K_{\mathrm{a} 1}$ from 7.86 to $8.4{ }^{67}$ At $\mathrm{pH} 6.5$ it has been reported that electrostatic and hydrogen bonding interactions between the amine of Dox and intrapolymer carboxyl groups can occur, which we believe is the case here between unconjugated HA carboxylate and Dox. ${ }^{68}$ Packing may also occur due to Dox-Dox stacking via $\pi-\pi$ interactions. ${ }^{68}$ Presumably, the packing, along with other chemical reactions described above resulted in the compacted size of the AuNP-HASHDox (50 nm), which is in the same size range as that of the AuNP-PEG $(48 \mathrm{~nm})$. The increase in diameter of the PNC $(60 \mathrm{~nm})$, the only complex with the aptamer, compared to that of the AuNP-HASHDox confirms not only the conjugation of the aptamer to the PEG but also the positioning of the aptamer, which most likely protrudes outside of the polymer shell. This boded well for the aptamer function as it made it more available, thus facilitating interactions with the targeted cellular receptor. The PDI of the nanoparticle conjugates were calculated from the DLS values and are shown in Table S3. The change in the zeta potential values provided further evidence of the effect of conjugation resulting presumably from intramolecular nanoparticle interactions (Table S2). The conjugation of Dox to the HA polymer caused a decrease in the negative charge of AuNPHASH (from -44.1 to $-18.5 \mathrm{mV}$ ). The full complex had a zeta potential value $(-29.0 \mathrm{mV})$ that is more negatively charged than that of the AuNP-HASHDox because of the addition of the DNA aptamer.

Pentameric Nanoparticle Complex Releases Doxorubicin in a Controlled Fashion. A prominent flaw in Dox and many cancer chemotherapeutic agents is the nonspecific cytotoxicity of circulating drugs, for example, the increased cardiovascular risk associated with Dox. ${ }^{69}$ The presence of the acid-labile hydrazone linkage between HA and Dox provides a controllable release mechanism from the PNC at lysosomal $\mathrm{pH}$ $(\sim \mathrm{pH} 4.5)$ or lower intracellular $\mathrm{pH}$ associated with cancer cells. The PNC contains thiol-linked components (HASHDox) that can be released in the presence of the cellular glutathione at intracellular levels of $10 \mathrm{mM}$ in comparison to extracellular concentration which is $1-3$ orders of magnitude lower. $^{70,71}$ Therefore, in vitro analysis mimicking conditions found in the cytoplasm and intracellular compartments of the cytoplasm, such as early endosome $(\mathrm{pH} 7.0$ with $10 \mathrm{mM}$ glutathione), lysosome ( $\mathrm{pH} 4.5$ with and without $10 \mathrm{mM}$ glutathione), and extracellular conditions found in the blood stream ( $\mathrm{pH} 7.0)$ were performed. In each of the conditions mentioned above, the PNC was centrifuged to pellet the nanoparticles and the supernatant was measured by UV-vis spectrophotometry at $490 \mathrm{~nm}$ to determine the Dox concentration (Figure S11). At $\mathrm{pH} 7.0$, minimal release was observed over the $8 \mathrm{~h}$ period. However, at $\mathrm{pH} 4.5$ there was increased release over all of the time points tested when compared to the release observed at $\mathrm{pH}$ 7.0. Doxorubicin was released in higher amounts in the acidic conditions compared to that in the intracellular condition of $\mathrm{pH}$ 7.0. The above data indicated that the acid-labile release was more efficient than the glutathione-mediated thiol exchange under cellular conditions. At a condition that triggered both acidic and glutathionemediated release mechanisms, an additive effect was observed at $8 \mathrm{~h}$ of incubation but not at the $4 \mathrm{~h}$ time point, suggesting that the breakage of the acid-labile hydrazone bond happened more efficiently than the effect of glutathione. The PNC was incubated with excess $\beta$-mercaptoethanol to achieve full release of the thiolated polymers (HASH-Dox and PEG-aptamer) from AuNP, and the amount of Dox was measured after $24 \mathrm{~h}$. Interestingly, the PNC samples incubated in $\mathrm{pH} 4.5$ alone and $\mathrm{pH} 4.5$ with $10 \mathrm{mM}$ glutathione released 66 and $95 \%$ of loaded Dox, respectively. These compared well to the previously reported values obtained from a similar acid-labile thiolated Dox release mechanism. ${ }^{61}$ 

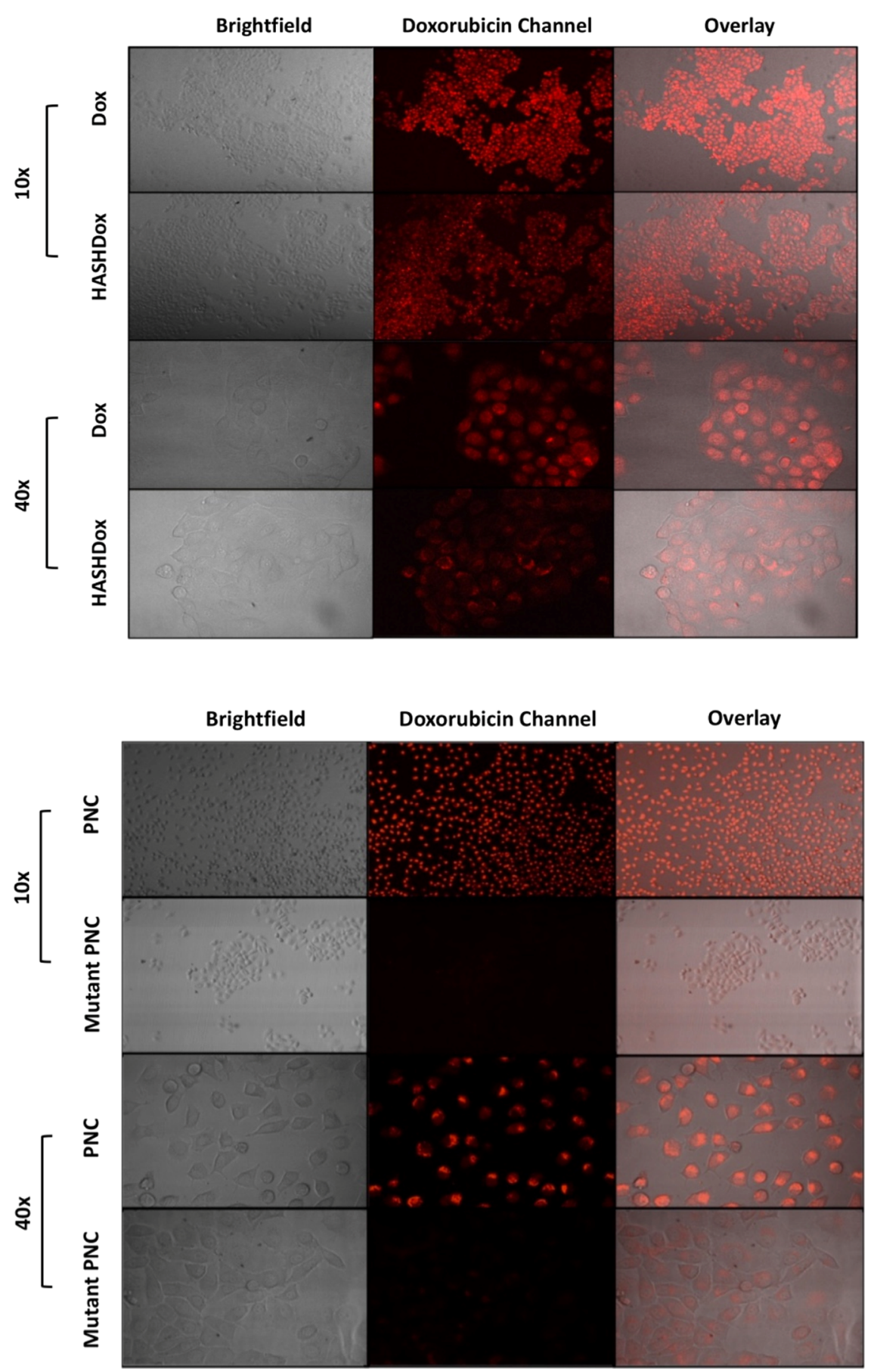

Figure 3. Cellular uptake of Dox is shown to be manipulated based on availability of CD44 aptamer and nanoparticle conjugation. Confocal images of HeLa cells after $12 \mathrm{~h}$ of treatment with (top) doxorubicin and HASH-Dox (bottom) PNC and mutant PNC at $1 \mu \mathrm{M}$.

Pentameric Nanoparticle Complex Preferentially Taken Up by CD44-Expressing Cancer Cells. The PNC was designed to specifically target CD44 overexpressing cancer and stem cells. To test the efficiency of cellular uptake of the PNC, we tested two cells lines, a known CD44 positive cell line HeLa and NIH3T3, a cell line known for low CD44 expression. The cells were incubated with Dox, HASH-Dox, PNC, and mutant PNC (contained a randomized version of the DNA aptamer sequence) for $12 \mathrm{~h}$ in $1 \mu \mathrm{M}$ Dox. The cells were washed with full media and immediately viewed under a confocal microscope to determine the intracellular Dox signal. Doxorubicin, HASH-Dox, and the PNC all showed substan- tially higher Dox signal in the CD44 overexpressing HeLa cells, when compared to the Dox signal in the mutant PNC-treated cells. The lower Dox signal in the mutant PNC-treated HeLa cells suggested aptamer-mediated targeting (Figure 3 ). Without the targeting aptamer, the mutant PNC would probably be too large for high levels of endocytosis. ${ }^{72,73}$ Additionally, the overall negative charge of the PNC is detrimental to nonspecific cellular uptake. $^{74}$ The targeted delivery of the Dox was further investigated by treating the low CD44-expressing NIH3T3 cells. Compared with Dox alone, all three Dox complexes (HASH-Dox, PNC, and mutant PNC) exhibited substantially lower uptake (Figure S12), indicating the essential nature of the 
CD44 receptor for the cellular delivery of conjugated Dox. Thus, the use of the larger nanoparticle complex paired with a targeting aptamer allowed for uptake comparable to that of free Dox with enhanced cellular selectivity that has the potential to greatly reduce off target side effects.

Hyaluronic acid had been used as a targeting molecule because it is the cognate ligand for the CD44 receptor. $^{75}$ However, in the PNC, the role of HA is to act as a drug loading polymer and stabilizer of the AuNP. That the HA did not play any role in cellular uptake of the complex was established by the observation that the mutant PNC showed very little cellular uptake in CD44 overexpressing cells. Thus, the enhanced uptake of the PNC is solely due to the presence of the CD44 aptamer and not HA. Additionally, the increased drug loading on the HA may also compromise the binding to the CD44 receptor. The HA can also interact with the conjugated Dox, as discussed previously, further reducing its ability to bind to the CD44 receptor. Thus, for the reasons stated above, HA most likely acted as a polymeric drug-loaded scaffold and not a targeting ligand.

Pentameric Nanoparticle Complex Demonstrates Selective Cellular Toxicity. To investigate the functional consequence of cell specific targeting, we examined differences in cellular viability when treated with the PNC, mutant PNC, and free Dox. Known CD44 overexpressing tumorigenic cell lines SKOV-3, C13, and HeLa were used to test cell specific toxicity, whereas NIH3T3 and SH-SY5Y cell lines were chosen as negative controls. Cellular viability assays using 3-(4,5dimethylthiazol-2-yl)-5-(3-carboxymethoxyphenyl)-2-(4-sulfophenyl)-2H-tetrazolium, inner salt analysis showed that the PNC outperformed the mutant PNC in CD44 overexpressing cell lines (Figure S13), whereas control cells showed similar viability in presence of the compounds that were tested. In CD44 overexpressing cell lines, SKOV-3 had a 4.5-fold increase in cell cytotoxicity based upon the fact that the PNC and mutant PNC had $\mathrm{IC}_{50}$ values of 62 versus $270 \mathrm{nM}$, respectively (Figure S14). The PNC had a similar preference for the CD44 overexpressing C13, a cisplatin-resistant A2008 ovarian cancer cell line, and HeLa when compared with the mutant complex. The $\mathrm{IC}_{50}$ values for $\mathrm{C} 13$ were 168 and $462 \mathrm{nM}$ (Figure S15), whereas for HeLa they were 138 and $315 \mathrm{nM}$ (Figure 4) for the active PNC and mutant, respectively. However, virtually no

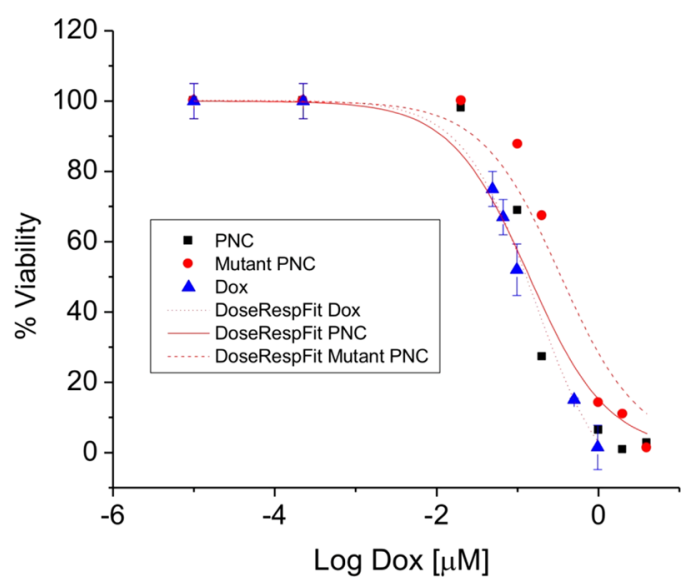

Figure 4. PNC complex is equally as cytotoxic as Dox in HeLa cells. Cellular viability study of HeLa cells treated with PNC, mutant PNC, and Dox. Experiments were performed in triplicates and $\mathrm{IC}_{50}$ values were calculated using a MTS assay $72 \mathrm{~h}$ post treatment. differences in cell viability were observed in the control cell lines. The $\mathrm{IC}_{50}$ values for PNC and mutant PNC were found to be 57 and $59 \mathrm{nM}$ in NIH3T3 and 600 and $700 \mathrm{nM} \mathrm{SH-SY5Y}$ cells, respectively (Figures S16 and S17), indicating virtually no difference in cytotoxicity of the two nanocomplexes.

Because of differences that may potentially exist in the extent of cellular endocytosis among different cell lines, $\mathrm{IC}_{50}$ values of the PNC were normalized against the $\mathrm{IC}_{50}$ values for the free Dox for each of the cell lines that was tested (Figure 5, top). In the case of the CD44 overexpressing cell lines, the PNC was equal to or more efficient than free Dox. However, when comparing such values to low CD44-expressing cell lines, the PNC showed values 2- and 5-fold less than the values for free Dox, indicating that overall the PNC is better in targeted delivery of the Dox to the CD44 overexpressing cell lines. The comparison between the $\mathrm{IC}_{50}$ values of the PNC versus the mutant complex further indicates the effectiveness of the CD44 aptamer (Figure 5, middle). Cells lines that overexpressed CD44 showed that the PNC was 2-4 times more lethal than the mutant PNC; however, interestingly, the two complexes were equally cytotoxic to the low CD44-expressing cell lines. The cytotoxicity was observed to drop between 2- and 4-fold in all cell lines when the values of the mutant PNC was compared to those of free Dox, indicating that the mutant PNC has lower cytotoxicity (Figure 5, bottom). Together, these results showed two important paradigms that demonstrated the functional effectiveness of this nanoparticle system. Doxorubicin, along with many other chemotherapeutic small molecules, can passively diffuse through the cell membrane, making entry favorable. ${ }^{76,77}$ The large size of the PNC most likely made normal endocytosis unfavorable as the membrane presumably is not able to fully engulf the nanoparticles, ${ }^{78,79}$ which is bypassed by use of the CD44 aptamer to participate in a receptormediated endocytosis. The nanoparticle system showed that it can be advantageous in the reduction of passive diffusion of Dox in nontargeted cells while being readily taken up in targeted cells.

PNC Reduces Self-Renewal. On the basis of the reduction in proliferation of CD44-expressing cancer cells, we wanted to evaluate if self-renewal could be impacted by the PNC. We utilized a TNBC CSC reporter system we developed whereby the CSC state is measured via the activity of the NANOG promoter-driven green fluorescence protein expression. When we treated CSCs with the PNC, we observed a reduction in self-renewal and the stem cell frequency from 1 in 14.9 to 1 in 25 with $20 \mathrm{nM}$ PNC and 1 in 23.6 to 1 in 43.6 with $200 \mathrm{nM}$ $\mathrm{PNC}$ in CSCs as compared with control treatment, with doxorubicin alone (Figure $6 \mathrm{~A}$ ). However, this reduction was not observed in non-CSCs (Figure 6B). Taken together, these data suggest that the PNC has the capacity to attenuate CSC self-renewal. As CSCs are becoming increasingly important in understanding and treating the tumorigenic environment, research on other therapeutic approaches has been achieved. An investigation using a combinatorial EpCAM aptamer-siRNA conjugate to sensitize CSCs showed improved Dox effectiveness in vivo. ${ }^{80}$ Another report explored a Docetaxel-modified HA drug conjugate, showing a slight improvement in MCF-7 CSCs versus normal MCF-7 cells but almost a 2-fold decrease in efficacy compared to that of the free drug, ${ }^{81}$ wherein the investigated PNC displayed the same efficacy compared to that of the free drug at a 10 -fold reduction in concentration in the tested TNBC CSCs. This highlights the potential role the PNC has as an improved vehicle for chemotherapeutic targeting of 

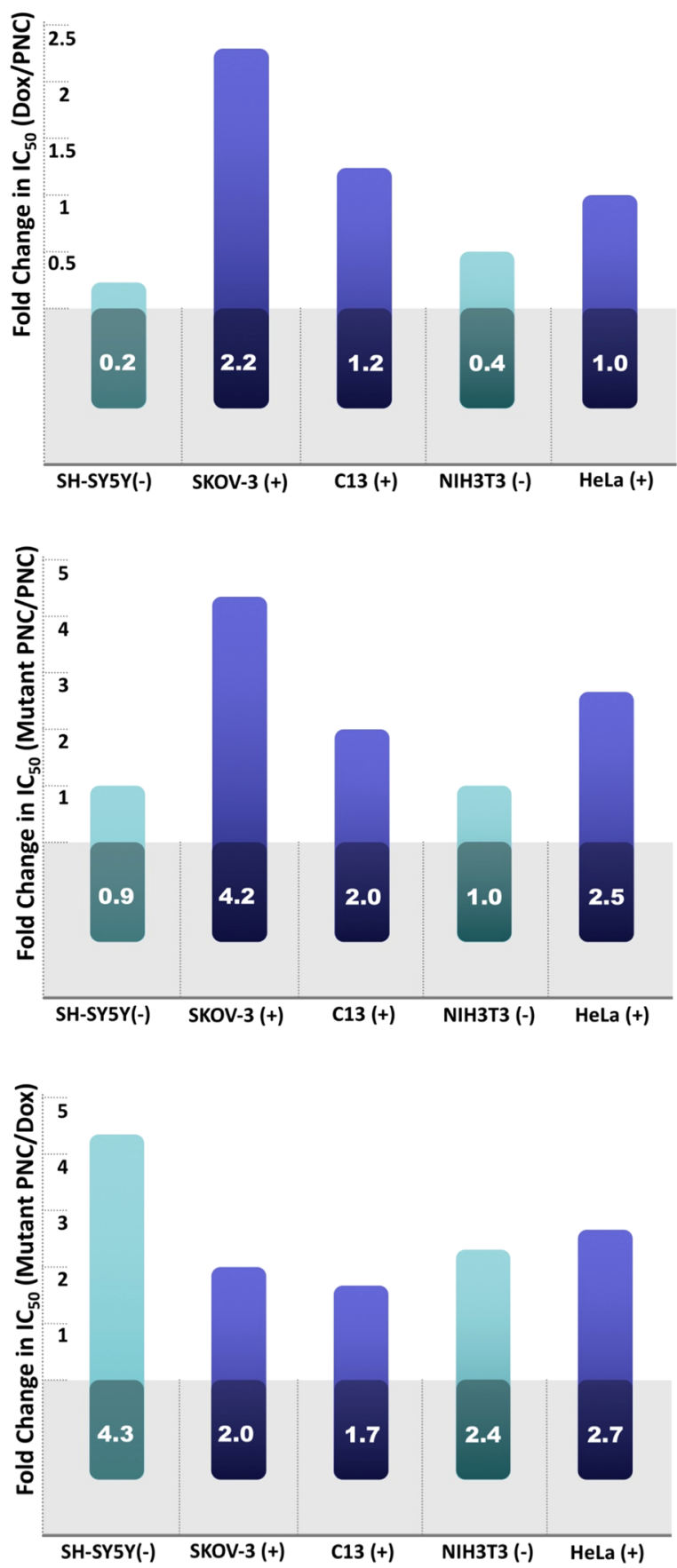

Figure 5. PNC complex is more cytotoxic than Dox in CD44 overexpressing cancer cells while showing an aptamer-dependent reduction in toxicity in low CD44-expressing CD44 cells. A comparison of MTS $\mathrm{IC}_{50}$ of the PNC, mutant PNC, and Dox in five separate cell lines varying in the CD44 expression were compared. (Top) The PNC IC 50 was normalized against Dox, signifying the PNC complex outperforms Dox in cells with CD44 overexpression (+) and being less effective in low CD44-expressing cells $(-)$. (Middle) PNC was 2-4.2 times more effective in CD44+ cells while maintaining the same cytotoxicity in low CD44-expressing cells, showing the dependence on the CD44 aptamer incorporation in the PNC. (Bottom) Across all cell lines, Dox was roughly 2-4.3 times more cytotoxic than the mutant PNC, representing the potential reduction in nonspecific target cytotoxicity.

CSCs and its role in the potential-improved tumorigenic treatment.

\section{CONCLUSIONS}

In summary, we designed and synthesized a PNC that is stable in high salt and selectively delivers small molecule chemotherapeutics to CD44+ cancer cells and CSCs. The naturally occurring polymer HA helped increase the drug loading as well as provided stability to the AuNP, preventing its precipitation in salt. By using a dual derivatized HA polymer, we were able to eliminate competition for drug and polymer loading on the gold surface while facilitating a controllable release mechanism with acid-labile hydrazone bonds on the HA, which allowed their release at low lysosomal $\mathrm{pH}$ and in the presence of physiologically relevant glutathione concentration. Cellular uptake and cell viability data demonstrated the role of the PEGylated DNA aptamer in targeting CD44 cell surface receptor-containing cancer cells. Remarkably, the active PNC showed almost an order of magnitude advantage between the CD44+ cells versus the cells that express CD44 poorly. A 10fold advantage in Dox efficacy can be highly beneficial in its use, as the reported cardiotoxicity limits its utility as an anticancer agent. Finally, the PNC was able to show a distinct cytotoxic effect on the CSCs in comparison with the mutant PNC. This will provide an additional benefit in terms of anticancer efficacy of the PNC. Overall, a novel five-part nanocomplex showed selective cytotoxicity toward CD44+ cancer and CSCs in combination with its reduced cytotoxicity toward nontargeted cells making the PNC a powerful anticancer drug delivery system. $^{56}$

\section{EXPERIMENTAL SECTION}

High molecular weight hyaluronic acid was purchased from Glycosan Biosystems (Salt Lake, UT). Bifunctionalized poly(ethylene glycol) with thiol and amine functionalizations, $\mathrm{N}$-(3(dimethylamino)propyl)- $N^{\prime}$-ethylcarbodiimide hydrochloride (EDC), N-hydroxysuccinimide (NHS), sodium borohydride, deuterium oxide $\left(\mathrm{D}_{2} \mathrm{O}\right)$, and bovine hyaluronidase were purchased from Sigma-Aldrich; doxorubicin hydrochloride, auric chloride $\left(\mathrm{HAuCl}_{3}\right)$, and adipic dihydrazide were purchased from Fischer Scientific. Dulbecco's modified Eagle's medium (DMEM) with 4.5 and $1 \mathrm{mg} / \mathrm{mL}$ L-glutamine, RPMI 1640 medium with L-glutamine, fetal bovine serum (FBS) were purchased from Worldwide Medical Supplies. CD44-directed DNA aptamer and the randomized version of the aptamer sequence were purchased from Integrated DNA Technologies (IDT). The Milli-Q water used in all experiments was obtained from a three-stage Millipore Milli-Q plus 185 purification system (Millipore Corporation), with a resistivity greater than $18.2 \mathrm{M} \Omega \mathrm{cm}$.

Preparation of Gold Nanoparticles. $\mathrm{HAuCl}_{3}(1.25 \mathrm{~mL}$, $50 \mathrm{mM}$ ) in $125 \mathrm{~mL}$ of deionized water was added to $1.4 \mathrm{~mL}$ of a sodium borohydride $(52 \mathrm{mM})-\mathrm{NaOH}(500 \mathrm{mM})$ solution and stirred overnight. The clear solution turned into a dark red color characteristic of smaller size gold nanoparticles (AuNPs). The solution was then filter-sterilized using a $0.2 \mu \mathrm{m}$ cellulose acetate filter (Corning). Ten kilodalton membrane cutfoff 50 $\mathrm{mL}$ centrifuge tubes were used to concentrate the nanoparticle solution to $2 \mathrm{~mL}$. The particle size was then analyzed by UVvis spectrophotometry, TEM, and dynamic light scattering (DLS). A known molar extinction coefficient was used to obtain nanoparticle concentration via UV-vis spectrophotometry.

Preparation of Thiolated Low Molecular Weight Hyaluronic Acid. High molecular weight $(\sim 500 \mathrm{kDa}) \mathrm{HA}$ 


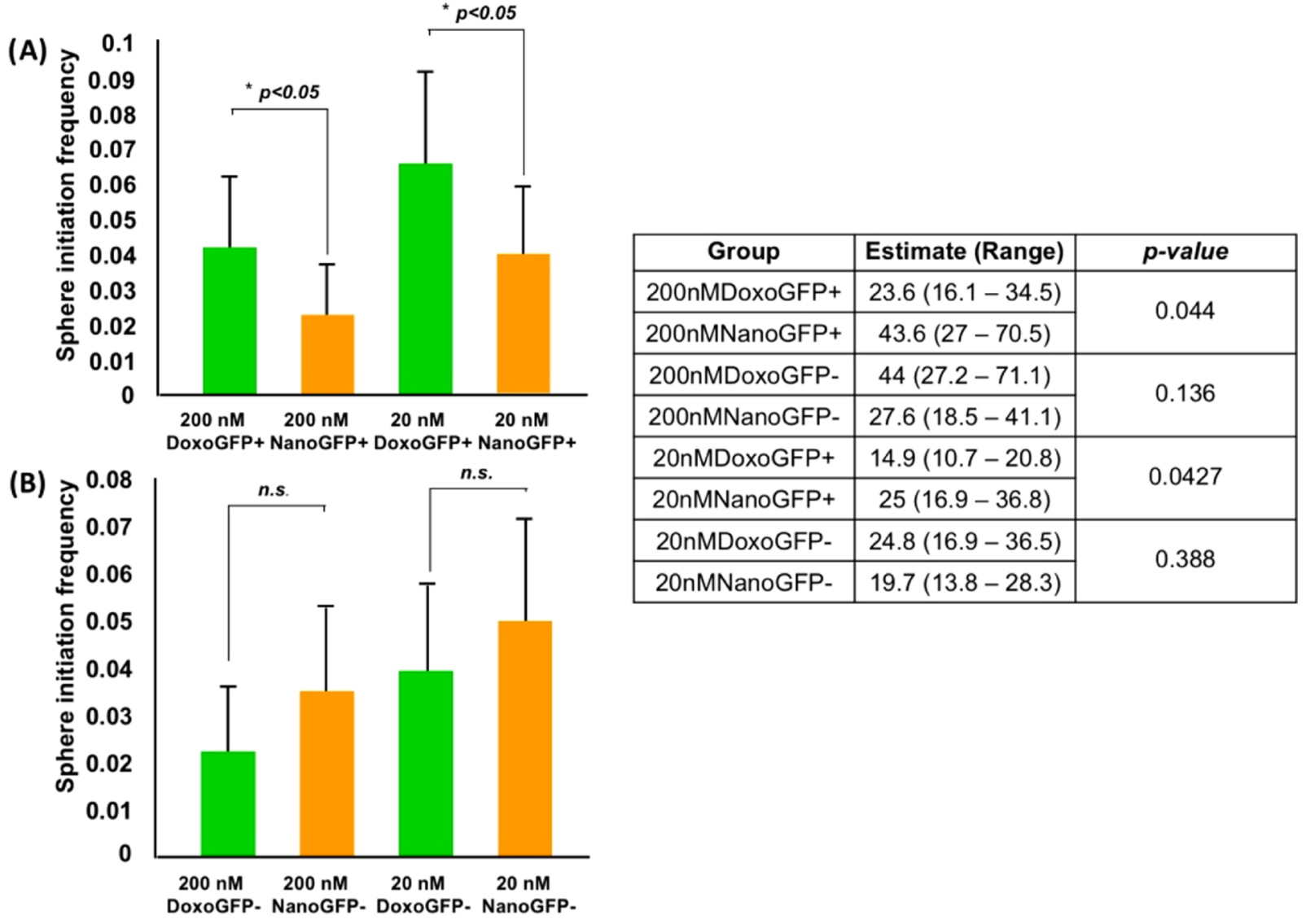

Figure 6. PNC is more cytotoxic in CD44+ CSCs compared to free drug. The limiting dilution assay performed on (A) CD44+ CSCs and (B) CD44- CSCs in the presence of PNC and free Dox. The PNC complex showed similar efficacy as that of Dox at a 10-fold reduction in concentration when comparing sphere initiation frequency across concentrations.

was subjected to degradation by bovine hyaluronidase according to a previously published procedure. ${ }^{82}$ Briefly, $2 \mathrm{~g}$ of high molecular weight $\mathrm{HA}$ was dissolved in $500 \mathrm{~mL}$ of phosphate-buffered saline $\mathrm{pH} 6.5$ containing bovine hyaluronidase (10 units/mg of HA). The digestion was carried out at $37{ }^{\circ} \mathrm{C}$ for $24 \mathrm{~h}$, after which the bovine hyaluronidase was inactivated by heating the solution to $95{ }^{\circ} \mathrm{C}$ for $20 \mathrm{~min}$. The resulting solution was then filter-sterilized using a $0.2 \mu \mathrm{m}$ cellulose acetate filter. The reaction mixture was then dialyzed in a $3.5 \mathrm{kDa}$ MWCO cellulose acetate membrane to remove salts. The dialyzed solution was then filtered using a $30 \mathrm{kDa}$ Amicon filter. The collected flow-through was then lyophilized overnight to obtain low molecular weight $\mathrm{HA}$, with an approximate size range of $3.5-30 \mathrm{kDa}$. The low molecular weight $\mathrm{HA}$ was then thiolated at the reducing end using a modified version of a previously published procedure. ${ }^{42}$ Forty five milligrams of $3.5-30 \mathrm{kDa} \mathrm{HA}$ and $60 \mathrm{mg}$ of cystamine were dissolved in $50 \mathrm{~mL}$ of borate-buffered saline at $\mathrm{pH} 8.5$ to facilitate the formation of the Schiff's base intermediate. The reaction mixture was incubated at $37{ }^{\circ} \mathrm{C}$ for $24 \mathrm{~h}$, after which the Schiff's base was reduced to the stable imine by the addition of sodium cyanoborohydride $(380 \mathrm{mg})$. The reduction reaction was carried out at $37{ }^{\circ} \mathrm{C}$ for $24 \mathrm{~h}$ in the dark. Cystamine disulfide linkages were then reduced by the addition of $10 \mathrm{M}$ equivalents of dithiothreitol with respect to cystamine. Salts and excess reagents were removed by dialysis using a $3.5 \mathrm{kDa}$ MWCO membrane. The resulting end thiolated, low molecular weight HA solution was lyophilized to obtain a white cottonlike solid. The level of end thiolation of $\mathrm{HA}$ was then determined using Ellman's method, a colorimetric assay commonly used to detect free thiols, according to the manufacturer's protocol (Thermo Scientific). The molecular weight of the digested and filter $\mathrm{HASH}$ was assessed to be 10 $\mathrm{kDa}$.

Synthesis of Modified Thiolated Hyaluronic Acid and Its Conjugation to Doxorubicin. End thiolated HA was modified by reacting to adipic dihydrazide. Hundred milligrams of HASH was added to $20 \mathrm{~mL}$ of 2-( $N$-morpholino)ethanesulfonic acid buffer ( $\mathrm{pH} 4.4$ ), $100 \mathrm{mg}$ of EDC, and 1.2 $\mathrm{g}$ of adipic dihydrazide. The solution was covered and stirred for 5 days. The reaction was then purified through dialysis using $3.5 \mathrm{kDa}$ cutoff dialysis bags for 3 days, changing the water every $12 \mathrm{~h}$. The remaining solution was then lypholized till a dry product was formed, which is covered and stored at $-20{ }^{\circ} \mathrm{C}$. Fifteen milligrams of the product (HASH-ADH) was added to $5 \mathrm{~mL}$ of water, $50 \mu \mathrm{L}$ of glacial acetic acid, and $2.5 \mathrm{mg}$ of Dox. The solution was covered and stirred for 5 days. Afterward, the reaction was purified via dialysis using a $3.5 \mathrm{kDa}$ dialysis bag for 3 days against water, changing water every $12 \mathrm{~h}$. The remaining solution was then lyophilized till a dry product was formed, which was covered and stored at $-20{ }^{\circ} \mathrm{C}$. UV-vis spectrophotometry, NMR, and infrared spectrometry were performed to establish Dox conjugation and Schiff base formation.

Poly(ethylene glycol) Aptamer Conjugation. 3'-Aminefunctionalized CD44 thioaptamer (CCA*A*GGCCTGCA*A*GGGA*A*CCA*A*GGA*CA*CA*G/3AmMO/) and mutant aptamer (NNNNNNNNNNNNNNNNNNNNNN- 
NNNNNNN/3AmMO/) were purchased from IDT. A 1.5:1 molar ratio (PEG to DNA) was mixed with excess of EDC and NHS in water over $24 \mathrm{~h}$ at room temperature to perform a coupling reaction. The PEG-conjugated aptamer was purified via $10 \mathrm{kDa} \mathrm{MWCO}$ centrifuge tubes. The conjugation was later established via a gel shift assay.

Synthesis of the Pentameric Nanocomplex (PNC). One AuNP to 1.5 PEG-aptamer molar ratio was added and shaken for $15 \mathrm{~min}$. Hundred microliters of a $5 \mathrm{mg} / \mathrm{mL}$ solution of HASH-Dox was added to the solution and shaken overnight. The PNC was purified by dialysis with $100000 \mathrm{kDa}$ MWCO centrifuge tubes (Millipore).

Dynamic Light Scattering (DLS) and Zeta Potential Measurements. The nanoparticle size was measured using a Nanopartica Nanoparticle Analyzer SZ-100 (Horiba Scientific). For size measurement, $5 \mu \mathrm{L}$ of each sample (AuNP, AuNPHASH, AuNP-HASHDox, PNC, and AuNP-PEG) were diluted up to $2 \mathrm{~mL}$ with water ( $\mathrm{pH} 6.5$ ) in $3 \mathrm{~mL}$ cuvettes. Size measurements were performed thrice with each trial done in triplicates, which then were averaged. For zeta potential measurements, the samples were diluted in water and dispersed in the zeta potential capsules. The samples were measured by using a Nanopartica Nanoparticle Analyzer SZ-100 (Horiba Scientific).

Detection of Nanoparticle Complexes by Agarose Gel. The 5'-end-radiolabeled single-stranded oligonucleotides were prepared by reacting the DNA with $\mathrm{T} 4$ polynucleotide kinase (NEB) and $\left[\gamma^{-}{ }^{32} \mathrm{P}\right] \mathrm{ATP}$ (PerkinElmer) for $45 \mathrm{~min}$ at 37 ${ }^{\circ} \mathrm{C}$. The radiolabeled DNA oligonucleotides were purified by $17 \%$ denaturing PAGE and extracted from the gel via the crush and soak method. The labeled aptamer was conjugated onto the nanoparticle. The samples were analyzed on an $1 \%$ agarose gel. The gel was exposed to a phosphorimager screen and then visualized by Typhoon Phosphorimager FLA 9500 (GE Healthcare, Life Sciences).

Stability of the Pentameric Nanoparticle Complex in Salt. Five microliters of the PNC was added to varying concentrations of $\mathrm{NaCl}$ solutions starting at $10 \mathrm{mM}$ and ending $1 \mathrm{M}$. The samples were incubated for $12 \mathrm{~h}$ at room temperature. Nanoparticle stability was visually assessed in comparison to a no salt control, along with $\mathrm{UV}-$ vis readings comparing any shifts at the AuNP peak maxima.

Release of Doxorubicin from the Pentameric Nanoparticle Complex. Solutions of the sample PNC $(25 \mu \mathrm{L})$ were incubated with phosphate-buffered saline $(75 \mu \mathrm{L})$ at $\mathrm{pH}$ 7.4 and $\mathrm{pH} 5.0$ or phosphate buffer $(65 \mu \mathrm{L})$ at $\mathrm{pH} 7.4$ and $\mathrm{pH}$ 5.0 with $100 \mathrm{mM}$ glutathione $(10 \mu \mathrm{L})$ for various time points. To achieve full drug release, $25 \mu \mathrm{L}$ of the sample of PNC was incubated with $75 \mu \mathrm{L}$ of $\beta$-mercaptethonal for $1 \mathrm{~h}$. Samples were centrifuged at $16000 \mathrm{rpm}$ to pellet AuNPs. The concentration of the released doxorubicin in the supernatant was then measured by UV-vis spectrophotometry. The percentage of drug release for each sample was then calculated as the percent absorbance at $490 \mathrm{~nm}$ (absorbance maxima of doxorubicin) compared to the full drug release control.

Antiproliferative Activity of the Pentameric Nanoparticle Complex via MTS assay. Antiproliferative activities of the nanocomplexes were tested using HeLa, SKOV-3, C13, NIH3T3, and SH-SY5Y cell lines. SKOV-3 cells were cultured in RPMI media, C13 and SH-SY5Y were cultured with Eagle's minimal essential medium, and HeLa and NIH3T3 cells were cultured with low glucose DMEM. All media were supplemented with FBS (10\% by volume) and penicillin/ streptomycin $(100 \mu \mathrm{g} / \mathrm{mL})$. The cells were seeded and grown overnight in a 96-well plate at a density of 3000 cells per well at $37{ }^{\circ} \mathrm{C}, 5 \% \mathrm{CO}_{2}$ in a humidified incubator. Cells were then treated with media containing various concentrations of nanocomplexes or Dox for $72 \mathrm{~h}$. Cell viability was then analyzed using the CellTiter 96 AQueous Non-Radioactive Cell Proliferation Assay (MTS) according to the manufacturer's protocol (Promega). All experiments were performed in triplicate.

Cellular Uptake Detection by Confocal Fluorescence Microscopy. HeLa and NIH3T3 cells were seeded overnight at a density of 10000 and 25000 cells per well, respectively, in an eight-well chamber slide. Cells were then treated for $12 \mathrm{~h}$ with media containing $1 \mu \mathrm{M}$ of either Dox, HASH-Dox, PNC, or mutant PNC. The cells were then washed three times with full growth media and immediately analyzed for intracellular Dox distribution under an Olympus $1000 \times$ confocal microscope.

Limiting Dilution Assay. MDA-MB-231 NANOG-GFP cells were prepared as previously described ${ }^{4}$ and sorted into GFP-positive and GFP-negative groups via flow cytometry prior to use. The in vitro limiting dilution assay was performed, as previously described, using the extreme limiting dilution algorithm. In short, cells were plated at a density of $1,5,10$, and 20 cells per well in a 96-well plate and spheres were scored 1014 days after plating.

\section{ASSOCIATED CONTENT}

\section{Supporting Information}

The Supporting Information is available free of charge on the ACS Publications website at DOI: 10.1021/acsomega.7b01168.

Figure S1, UV-vis spectra of AuNP; Figure S2, TEM image of AuNP; Table S1, TEM sizing; Figure S3, conjugation of CD44 aptamer post addition of HASHDox; Figure S4, migration of aptamer and no aptamer nanocomplexes in 1\% agarose gel; Figure S5, UV-vis spectra of varying reaction conditions of HASH-Dox; Figure S6, ${ }^{1} \mathrm{H}$ NMR spectrum of HASH; Figure S7, ${ }^{1} \mathrm{H}$ NMR spectrum of HASH-Dox; Figure S8, IR spectrum of HASH; Figure S9, IR spectrum of HASH-Dox; Figure S10, UV-vis spectra of the PNC in increasing concentrations of $\mathrm{NaCl}$ to investigate nanoparticle stability; Table S2, zeta potential measurements of PNC and AuNP with the varying types of polymer derivatives; Table S3, PDI for nanoparticle conjugates; Figure S11, quantification of Dox release using UV-vis spectroscopy; Figure S12, confocal images of NIH3T3 cells after treatment with Dox, HASH-Dox, PNC, and mutant PNC; Figure S13, histograms to show $\mathrm{IC}_{50}$ values for the different cell lines; Figures S14-S17, cellular viability studies of SKOV-3, C13, SH-SY5Y, and NIH3T3 cell lines treated with PNC, mutant PNC and Dox (PDF)

\section{AUTHOR INFORMATION}

\section{Corresponding Author}

*E-mail: sbasu@kent.edu.

ORCID

Soumitra Basu: 0000-0001-6904-8019

Present Address

${ }^{\perp}$ Unichem Laboratories Ltd., Mumbai 400102, India (A.D.). 


\section{Author Contributions}

Experiments were performed by N.B., P.S.T., E.S., and A.D. Data analysis was performed by N.B., P.S.T., O.R., J.D.L., and S.B. The manuscript was written by N.B., J.D.L., and S.B.

\section{Notes}

The authors declare no competing financial interest.

\section{ABBREVIATIONS}

CSC, cancer stem cells; PNC, pentameric nanocomplex; AuNP, gold nanoparticles; Dox, doxorubicin; TNBC, triple negative breast cancer; pCR, pathologically complete response; EPR, enhanced permeability and retention; HA, hyaluronic acid; DLS, dynamic light scattering; $\mathrm{HASH}$, thiolated hyaluronic acid; HASH-Dox, thiolated hyaluronic acid-doxorubicin; $\mathrm{ADH}$, adipic dihydrazide

\section{REFERENCES}

(1) Bareford, L. M.; Swaan, P. W. Endocytic mechanisms for targeted drug delivery. Adv. Drug Delivery Rev. 2007, 59, 748-758.

(2) Ponta, H.; Sherman, L.; Herrlich, P. A. CD44: from adhesion molecules to signalling regulators. Nat. Rev. Mol. Cell Biol. 2003, 4, $33-45$.

(3) Hong, I.-S.; Jang, G.-B.; Lee, H.-Y.; Nam, J.-S. Targeting cancer stem cells by using the nanoparticles. Int. J. Nanomed. 2015, 10, 251260.

(4) Thiagarajan, P. S.; Hitomi, M.; Hale, J. S.; Alvarado, A. G.; Otvos, B.; Sinyuk, M.; Stoltz, K.; Wiechert, A.; Mulkearns-Hubert, E.; Jarrar, A. M.; Zheng, Q.; Thomas, D.; Egelhoff, T. T.; Rich, J. N.; Liu, H.; Lathia, J. D.; Reizes, O. Development of a Fluorescent Reporter System to Delineate Cancer Stem Cells in Triple-Negative Breast Cancer. Stem Cells 2015, 33, 2114-2125.

(5) Wang, L.; Su, W.; Liu, Z.; Zhou, M.; Chen, S.; Chen, Y.; Lu, D.; Liu, Y.; Fan, Y.; Zheng, Y.; Han, Z.; Kong, D.; Wu, J. C.; Xiang, R.; Li, Z. CD44 antibody-targeted liposomal nanoparticles for molecular imaging and therapy of hepatocellular carcinoma. Biomaterials 2012, 33, 5107-5114.

(6) Jain, A.; Jain, S. K. In vitro and cell uptake studies for targeting of ligand anchored nanoparticles for colon tumors. Eur. J. Pharm. Sci. 2008, 35, 404-416.

(7) Jain, A.; Jain, S. K.; Ganesh, N.; Barve, J.; Beg, A. M. Design and development of ligand-appended polysaccharidic nanoparticles for the delivery of oxaliplatin in colorectal cancer. Nanomedicine 2010, 6, 179-190.

(8) Chen, J.; Zhou, J.; Lu, J.; Xiong, H.; Shi, X.; Gong, L. Significance of CD44 expression in head and neck cancer: a systemic review and meta-analysis. BMC Cancer 2014, 14, 15.

(9) Shah, V.; Taratula, O.; Garbuzenko, O. B.; Taratula, O. R.; Rodriguez-Rodriguez, L.; Minko, T. Targeted nanomedicine for suppression of CD44 and simultaneous cell death induction in ovarian cancer: an optimal delivery of siRNA and anticancer drug. Clin. Cancer Res. 2013, 19, 6193-6204.

(10) Jaggupilli, A.; Elkord, E. Significance of CD44 and CD24 as Cancer Stem Cell Markers: An Enduring Ambiguity. Clin. Dev. Immunol. 2012, 2012, 1-11.

(11) de Beça, F. F.; Caetano, P.; Gerhard, R.; Alvarenga, C. A.; Gomes, M.; Paredes, J.; Schmitt, F. Cancer stem cells markers CD44, CD24 and ALDH1 in breast cancer special histological types. J. Clin. Pathol. 2013, 66, 187-191.

(12) Idowu, M. O.; Kmieciak, M.; Dumur, C.; Burton, R. S.; Grimes, M. M.; Powers, C. N.; Manjili, M. H. CD44(+)/CD24(-/low) cancer stem/progenitor cells are more abundant in triple-negative invasive breast carcinoma phenotype and are associated with poor outcome. Hum. Pathol. 2012, 43, 364-373.

(13) Otvos, B.; Silver, D. J.; Mulkearns-Hubert, E. E.; Alvarado, A. G.; Turaga, S. M.; Sorensen, M. D.; Rayman, P.; Flavahan, W. A.; Hale, J. S.; Stoltz, K.; Sinyuk, M.; Wu, Q.; Jarrar, A.; Kim, S. H.; Fox, P. L.; Nakano, I.; Rich, J. N.; Ransohoff, R. M.; Finke, J.; Kristensen, B. W.;
Vogelbaum, M. A.; Lathia, J. D. Cancer Stem Cell-Secreted Macrophage Migration Inhibitory Factor Stimulates Myeloid Derived Suppressor Cell Function and Facilitates Glioblastoma Immune Evasion. Stem Cells 2016, 34, 2026-2039.

(14) Meacham, C. E.; Morrison, S. J. Tumour heterogeneity and cancer cell plasticity. Nature 2013, 501, 328-337.

(15) Wei, J.; Barr, J.; Kong, L. Y.; Wang, Y.; Wu, A.; Sharma, A. K.; Gumin, J.; Henry, V.; Colman, H.; Priebe, W.; Sawaya, R.; Lang, F. F.; Heimberger, A. B. Glioblastoma cancer-initiating cells inhibit T-cell proliferation and effector responses by the signal transducers and activators of transcription 3 pathway. Mol. Cancer Ther. 2010, 9, 6778.

(16) Sarkar, S.; Döring, A.; Zemp, F. J.; Silva, C.; Lun, X.; Wang, X.; Kelly, J.; Hader, W.; Hamilton, M.; Mercier, P.; Dunn, J. F.; Kinniburgh, D.; van Rooijen, N.; Robbins, S.; Forsyth, P.; Cairncross, G.; Weiss, S.; Yong, V. W. Therapeutic activation of macrophages and microglia to suppress brain tumor-initiating cells. Nat. Neurosci. 2014, 17, 46-55.

(17) Zhou, W.; Ke, S. Q.; Huang, Z.; Flavahan, W.; Fang, X.; Paul, J.; Wu, L.; Sloan, A. E.; McLendon, R. E.; Li, X.; Rich, J. N.; Bao, S. Periostin secreted by glioblastoma stem cells recruits M2 tumourassociated macrophages and promotes malignant growth. Nat. Cell Biol. 2015, 17, 170-182.

(18) Silver, D. J.; Sinyuk, M.; Vogelbaum, M. A.; Ahluwalia, M. S.; Lathia, J. D. The intersection of cancer, cancer stem cells, and the immune system: therapeutic opportunities. Neuro-Oncology 2016, 18, $153-159$.

(19) Metzger-Filho, O.; Tutt, A.; de Azambuja, E.; Saini, K. S.; Viale, G.; Loi, S.; Bradbury, I.; Bliss, J. M.; Azim, H. A., Jr.; Ellis, P.; Di Leo, A.; Baselga, J.; Sotiriou, C.; Piccart-Gebhart, M. Dissecting the heterogeneity of triple-negative breast cancer. J. Clin. Oncol. 2012, 30, 1879-1887.

(20) Andre, F.; Zielinski, C. C. Optimal strategies for the treatment of metastatic triple-negative breast cancer with currently approved agents. Ann. Oncol. 2012, 23, vi46-vi51.

(21) Kalimutho, M.; Parsons, K.; Mittal, D.; Lopez, J. A.; Srihari, S.; Khanna, K. K. Targeted Therapies for Triple-Negative Breast Cancer: Combating a Stubborn Disease. Trends Pharmacol. Sci. 2015, 36, 822846.

(22) Yu, M. K.; Park, J.; Jon, S. Targeting strategies for multifunctional nanoparticles in cancer imaging and therapy. Theranostics 2012, 2, 3-44.

(23) Jain, S.; Hirst, D. G.; O’Sullivan, J. M. Gold nanoparticles as novel agents for cancer therapy. Br. J. Radiol. 2012, 85, 101-113.

(24) Teow, Y.; Valiyaveettil, S. Active targeting of cancer cells using folic acid-conjugated platinum nanoparticles. Nanoscale 2010, 2, 2607-2613.

(25) Abakumov, M. A.; Nukolova, N. V.; Sokolsky-Papkov, M.; Shein, S. A.; Sandalova, T. O.; Vishwasrao, H. M.; Grinenko, N. F.; Gubsky, I. L.; Abakumov, A. M.; Kabanov, A. V.; Chekhonin, V. P. VEGF-targeted magnetic nanoparticles for MRI visualization of brain tumor. Nanomedicine 2015, 11, 825-833.

(26) Yang, X.; Iyer, A. K.; Singh, A.; Choy, E.; Hornicek, F. J.; Amiji, M. M.; Duan, Z. MDR1 siRNA loaded hyaluronic acid-based CD44 targeted nanoparticle systems circumvent paclitaxel resistance in ovarian cancer. Sci. Rep. 2015, 5, No. 8509.

(27) Matsumura, Y.; Maeda, H. A new concept for macromolecular therapeutics in cancer chemotherapy: mechanism of tumoritropic accumulation of proteins and the antitumor agent smancs. Cancer Res. 1986, 46, 6387-6392.

(28) Perrault, S. D.; Walkey, C.; Jennings, T.; Fischer, H. C.; Chan, W. C. Mediating tumor targeting efficiency of nanoparticles through design. Nano Lett. 2009, 9, 1909-1915.

(29) Cheng, Y.; Meyers, J. D.; Agnes, R. S.; Doane, T. L.; Kenney, M. E.; Broome, P.; Burda, C.; Basilion, J. P. Addressing Brain Tumors with Targeted Gold Nanoparticles: A New Gold Standard for Hydrophobic Drug Delivery? Small 2011, 7, 2301-2306.

(30) Arosio, D.; Chiodo, F.; Reina, J. J.; Marelli, M.; Penades, S.; van Kooyk, Y.; Garcia-Vallejo, J. J.; Bernardi, A. Effective targeting of DC- 
SIGN by alpha-fucosylamide functionalized gold nanoparticles. Bioconjugate Chem. 2014, 25, 2244-2251.

(31) Low, S. A.; Yang, J.; Kopeček, J. Bone-Targeted Acid-Sensitive Doxorubicin Conjugate Micelles as Potential Osteosarcoma Therapeutics. Bioconjugate Chem. 2014, 25, 2012-2020.

(32) Adnan, N. N. M.; Cheng, Y. Y.; Ong, N. M. N.; Kamaruddin, T. T.; Rozlan, E.; Schmidt, T. W.; Duong, H. T. T.; Boyer, C. Effect of gold nanoparticle shapes for phototherapy and drug delivery. Polym. Chem. 2016, 7, 2888-2903.

(33) Liao, L.; Liu, J.; Dreaden, E. C.; Morton, S.; Shopsowitz, K. E.; Hammond, P. T.; Johnson, J. A. A Convergent Synthetic Platform for Single-Nanoparticle Combination Cancer Therapy: Ratiometric Loading and Controlled Release of Cisplatin, Doxorubicin, and Camptothecin. J. Am. Chem. Soc. 2014, 136, 5896-5899.

(34) Farokhzad, O. C.; Cheng, J.; Teply, B. A.; Sherifi, I.; Jon, S.; Kantoff, P. W.; Richie, J. P.; Langer, R. Targeted nanoparticle-aptamer bioconjugates for cancer chemotherapy in vivo. Proc. Natl. Acad. Sci. U.S.A. 2006, 103, 6315-6320.

(35) Alshaer, W.; Hillaireau, H.; Vergnaud, J.; Ismail, S.; Fattal, E. Functionalizing Liposomes with anti-CD44 Aptamer for Selective Targeting of Cancer Cells. Bioconjugate Chem. 2015, 26, 1307-1313. (36) Zhao, N.; You, J.; Zeng, Z.; Li, C.; Zu, Y. An Ultra pH-Sensitive and Aptamer-Equipped Nanoscale Drug-Delivery System for Selective Killing of Tumor Cells. Small 2013, 9, 3477-3484.

(37) Alkilany, A. M.; Murphy, C. J. Toxicity and cellular uptake of gold nanoparticles: what we have learned so far? J. Nanopart. Res. 2010, 12, 2313-2333.

(38) Daniel, M. C.; Astruc, D. Gold nanoparticles: assembly, supramolecular chemistry, quantum-size-related properties, and applications toward biology, catalysis, and nanotechnology. Chem. Rev. 2004, 104, 293-346.

(39) Häkkinen, $\mathrm{H}$. The gold-sulfur interface at the nanoscale. Nat. Chem. 2012, 4, 443-455.

(40) Hayward, S. L.; Wilson, C. L.; Kidambi, S. Hyaluronic acidconjugated liposome nanoparticles for targeted delivery to CD44 overexpressing glioblastoma cells. Oncotarget 2016, 7, 34158-34171.

(41) Lee, M. Y.; Yang, J. A.; Jung, H. S.; Beack, S.; Choi, J. E.; Hur, W.; Koo, H.; Kim, K.; Yoon, S. K.; Hahn, S. K. Hyaluronic acid-gold nanoparticle/interferon alpha complex for targeted treatment of hepatitis C virus infection. ACS Nano 2012, 6, 9522-9531.

(42) Lee, H.; Lee, K.; Kim, I. K.; Park, T. G. Synthesis, characterization, and in vivo diagnostic applications of hyaluronic acid immobilized gold nanoprobes. Biomaterials 2008, 29, 4709-4718.

(43) Maiolino, S.; Moret, F.; Conte, C.; Fraix, A.; Tirino, P.; Ungaro, F.; Sortino, S.; Reddi, E.; Quaglia, F. Hyaluronan-decorated polymer nanoparticles targeting the CD44 receptor for the combined photo/ chemo-therapy of cancer. Nanoscale 2015, 7, 5643-5653.

(44) Deng, Z. J.; Morton, S. W.; Ben-Akiva, E.; Dreaden, E. C.; Shopsowitz, K. E.; Hammond, P. T. Layer-by-Layer Nanoparticles for Systemic Codelivery of an Anticancer Drug and siRNA for Potential Triple-Negative Breast Cancer Treatment. ACS Nano 2013, 7, 95719584.

(45) Huang, W. Y.; Lin, J. N.; Hsieh, J. T.; Chou, S. C.; Lai, C. H.; Yun, E. J.; Lo, U. G.; Pong, R. C.; Lin, J. H.; Lin, Y. H. Nanoparticle Targeting CD44-Positive Cancer Cells for Site-Specific Drug Delivery in Prostate Cancer Therapy. ACS Appl. Mater. Interfaces 2016, 8, 30722-30734.

(46) Muntimadugu, E.; Kumar, R.; Saladi, S.; Rafeeqi, T. A.; Khan, W. CD44 targeted chemotherapy for co-eradication of breast cancer stem cells and cancer cells using polymeric nanoparticles of salinomycin and paclitaxel. Colloids Surf., B 2016, 143, 532-546.

(47) Sun, T. M.; Wang, Y. C.; Wang, F.; Du, J. Z.; Mao, C. Q.; Sun, C. Y.; Tang, R. Z.; Liu, Y.; Zhu, J.; Zhu, Y. H.; Yang, X. Z.; Wang, J. Cancer stem cell therapy using doxorubicin conjugated to gold nanoparticles via hydrazone bonds. Biomaterials 2014, 35, 836-845.

(48) Somasunderam, A.; Thiviyanathan, V.; Tanaka, T.; Li, X.; Neerathilingam, M.; Lokesh, G. L.; Mann, A.; Peng, Y.; Ferrari, M.; Klostergaard, J.; Gorenstein, D. G. Combinatorial selection of DNA thioaptamers targeted to the HA binding domain of human CD44. Biochemistry 2010, 49, 9106-9112.

(49) Campbell, J. M.; Bacon, T. A.; Wickstrom, E. Oligodeoxynucleoside phosphorothioate stability in subcellular extracts, culture media, sera and cerebrospinal fluid. J. Biochem. Biophys. Methods 1990, 20, $259-267$.

(50) Zhong, Y.; Zhang, J.; Cheng, R.; Deng, C.; Meng, F.; Xie, F.; Zhong, Z. Reversibly crosslinked hyaluronic acid nanoparticles for active targeting and intelligent delivery of doxorubicin to drug resistant CD44+ human breast tumor xenografts. J. Controlled Release 2015, 205, 144-154.

(51) Tannock, I. F.; Rotin, D. Acid pH in tumors and its potential for therapeutic exploitation. Cancer Res. 1989, 49, 4373-4384.

(52) Choi, H. S.; Liu, W.; Misra, P.; Tanaka, E.; Zimmer, J. P.; Ipe, B. I.; Bawendi, M. G.; Frangioni, J. V. Renal Clearance of Nanoparticles. Nat. Biotechnol. 2007, 25, 1165-1170.

(53) Bartczak, D.; Kanaras, A. G. Preparation of Peptide-Functionalized Gold Nanoparticles Using One Pot EDC/Sulfo-NHS Coupling. Langmuir 2011, 27, 10119-10123.

(54) Poon, Z.; Lee, J. B.; Morton, S. W.; Hammond, P. T. Controlling In Vivo Stability and Biodistribution in Electrostatically Assembled Nanoparticles for Systemic Delivery. Nano Lett. 2011, 11, 2096-2103.

(55) Prestwich, G. D. Hyaluronic acid-based clinical biomaterials derived for cell and molecule delivery in regenerative medicine. $J$. Controlled Release 2011, 155, 193-199.

(56) Sideris, E.; Griffin, D. R.; Ding, Y.; Li, S.; Weaver, W. M.; Carlo, D. D.; Hsiai, T.; Segura, T. Particle Hydrogels Based on Hyaluronic Acid Building Blocks. ACS Biomater. Sci. Eng. 2016, 2, 2034-2041.

(57) Zhu, L.; Yang, S.; Qu, X.; Zhu, F.; Liang, Y.; Liang, F.; Wang, Q.; Li, J.; Li, Z.; Yang, Z. Fibril-shaped aggregates of doxorubicin with poly-L-lysine and its derivative. Polym. Chem. 2014, 5, 5700-5706.

(58) Li, X.; Gao, C.; Wu, Y.; Cheng, C.-Y.; Xia, W.; Zhang, Z. Combination delivery of Adjudin and Doxorubicin via integrating drug conjugation and nanocarrier approaches for the treatment of drugresistant cancer cells. J. Mater. Chem. B 2015, 3, 1556-1564.

(59) Niskanen, J.; Karesoja, M.; Aseyev, V.; Qiu, X. P.; Winnik, F. M.; Tenhu, H. Thermal response of a PVCL-HA conjugate. J. Polym. Sci., Part A: Polym. Chem. 2016, 54, 425-436.

(60) Youm, I.; Agrahari, V.; Murowchick, J. B.; Youan, B. B. Uptake and cytotoxicity of docetaxel-loaded hyaluronic acid-grafted oily core nanocapsules in MDA-MB 231 cancer cells. Pharm. Res. 2014, 31, 2439-2452.

(61) Cheng, Y.; Dai, Q.; Morshed, R. A.; Fan, X.; Wegscheid, M. L.; Wainwright, D. A.; Han, Y.; Zhang, L.; Auffinger, B.; Tobias, A. L.; Rincon, E.; Thaci, B.; Ahmed, A. U.; Warnke, P. C.; He, C.; Lesniak, M. S. Blood-brain barrier permeable gold nanoparticles: an efficient delivery platform for enhanced malignant glioma therapy and imaging. Small 2014, 10, 5137-5150.

(62) Kanjanawarut, R.; Yuan, B.; XiaoDi, S. UV-vis spectroscopy and dynamic light scattering study of gold nanorods aggregation. Nucleic Acid Ther. 2013, 23, 273-280.

(63) Sato, T.; Ikeda, N.; Shirataka, M.; Miyahara, H.; Tsuruta, H.; Wada, T. Estimation of body water and salt contents from plasma sodium, protein concentrations, and hematocrit. Jpn. Heart J. 1979, 20, $853-866$.

(64) Dreaden, E. C.; Austin, L. A.; Mackey, M. A.; El-Sayed, M. A. Size matters: gold nanoparticles in targeted cancer drug delivery. Ther. Delivery 2012, 3, 457-478.

(65) Oh, E.; Delehanty, J. B.; Sapsford, K. E.; Susumu, K.; Goswami, R.; Blanco-Canosa, J. B.; Dawson, P. E.; Granek, J.; Shoff, M.; Zhang, Q.; Goering, P. L.; Huston, A.; Medintz, I. L. Cellular uptake and fate of PEGylated gold nanoparticles is dependent on both cell-penetration peptides and particle size. ACS Nano 2011, 5, 6434-6448.

(66) Mero, A.; Campisi, M. Hyaluronic Acid Bioconjugates for the Delivery of Bioactive Molecules. Polymers 2014, 6, 346-369.

(67) Sanli, S.; Altun, Y.; Guven, G. Solvent Effects on pKa Values of Some Anticancer Agents in Acetonitrile-Water Binary Mixtures. J. Chem. Eng. Data 2014, 59, 4015-4020. 
(68) Kitaeva, M. V.; Melik-Nubarov, N. S.; Menger, F. M.; Yaroslavov, A. A. Doxorubicin-poly(acrylic acid) complexes: interaction with liposomes. Langmuir 2004, 20, 6575-6579.

(69) Swain, S. M.; Whaley, F. S.; Ewer, M. S. Congestive heart failure in patients treated with doxorubicin: a retrospective analysis of three trials. Cancer 2003, 97, 2869-2879.

(70) Richie, J. P.; Skowronski, L.; Abraham, P.; Leutzinger, Y. Blood glutathione concentrations in a large-scale human study. Clin. Chem. 1996, 42, 64-70.

(71) Lushchak, V. I. Glutathione Homeostasis and Functions: Potential Targets for Medical Interventions. J. Amino Acids 2012, 2012, No. 736837.

(72) Zhang, S.; Li, J.; Lykotrafitis, G.; Bao, G.; Suresh, S. SizeDependent Endocytosis of Nanoparticles. Adv. Mater. 2009, 21, 419424.

(73) Zhang, S.; Gao, H.; Bao, G. Physical Principles of Nanoparticle Cellular Endocytosis. ACS Nano 2015, 9, 8655-8671.

(74) Blanco, E.; Shen, H.; Ferrari, M. Principles of nanoparticle design for overcoming biological barriers to drug delivery. Nat. Biotechnol. 2015, 33, 941-951.

(75) Peach, R. J.; Hollenbaugh, D.; Stamenkovic, I.; Aruffo, A. Identification of hyaluronic acid binding sites in the extracellular domain of CD44. J. Cell Biol. 1993, 122, 257-264.

(76) Rahman, A.; Carmichael, D.; Harris, M.; Roh, J. K. Comparative pharmacokinetics of free doxorubicin and doxorubicin entrapped in cardiolipin liposomes. Cancer Res. 1986, 46, 2295-2299.

(77) Szachowicz-Petelska, B.; Figaszewski, Z.; Lewandowski, W. Mechanisms of transport across cell membranes of complexes contained in antitumour drugs. Int. J. Pharm. 2001, 222, 169-182.

(78) Zhang, S.; Li, J.; Lykotrafitis, G.; Bao, G.; Suresh, S. SizeDependent Endocytosis of Nanoparticles. Adv. Mater. 2009, 21, 419424.

(79) Racine, R.; Mummert, M. E. Molecular Regulation of Endocytosis. Rep. Pract. Oncol. Radiother. 2012, 378-390.

(80) Wang, T.; Gantier, M. P.; Xiang, D.; Bean, A. G.; Bruce, M.; Zhou, S. F.; Khasraw, M.; Ward, A.; Wang, L.; Wei, M. Q.; AlShamaileh, H.; Chen, L.; She, X.; Lin, J.; Kong, L.; Shigdar, S.; Duan, W. EpCAM Aptamer-mediated Survivin Silencing Sensitized Cancer Stem Cells to Doxorubicin in a Breast Cancer Model. Theranostics 2015, 5, 1456-1472.

(81) Goodarzi, N.; Ghahremani, M. H.; Amini, M.; Atyabi, F.; Ostad, S. N.; Shabani Ravari, N.; Nateghian, N.; Dinarvand, R. CD44Targeted Docetaxel Conjugate for Cancer Cells and Cancer Stem-Like Cells: A Novel Hyaluronic Acid-Based Drug Delivery System. Chem. Biol. Drug Des. 2014, 83, 741-752.

(82) Luo, Y.; Prestwich, G. D. Synthesis and selective cytotoxicity of a hyaluronic acid-antitumor bioconjugate. Bioconjugate Chem. 1999, $10,755-763$. 